\title{
Decompressive craniectomy in massive cerebral infarction
}

\author{
João Paulo Mattos ${ }^{1}$, Andrei Fernandes Joaquim², \\ João Paulo Cavalcante de Almeida ${ }^{3}$, \\ Lucas Alverne Freitas de Albuquerque ${ }^{4}$, Élton Gomes da Silva², \\ Horácio Armando Marenco ${ }^{2}$, Evandro de Oliveira ${ }^{5}$
}

\begin{abstract}
Twenty one patients were submitted to decompressive craniectomy for massive cerebral infarct. Ten patients (47.6\%) presented a good outcome at the 6 months evaluation, eight had a poor outcome (38\%) and three died (14.2\%). There was no outcome statistical difference between surgery before and after 24 hours of ictus, dominant and non-dominant stroke groups. Patients older than 60 years and those who had a Glasgow Coma Scale (GCS) $<8$ in the pre-surgical exam presented worst outcome at six months $(p<0.05)$. Decompressive craniectomy for space-occupying large hemispheric infarction increases the probability of survival. Age lower than 60 years, GCS $\geq 8$ at pre-surgical exam and decompressive craniectomy before signs of brain herniation represent the main factors related to a better outcome. Dominant hemispheric infarction does not represent exclusion criteria. Key words: cerebral infarction, decompressive hemicraniectomy, surgical decompression.
\end{abstract}

\section{Craniectomia descompressiva no infarto cerebral extenso}

\section{RESUMO}

Vinte e um pacientes foram submetidos a craniectomia descompressiva para o tratamento de infarto cerebral extenso. Dez pacientes $(47,6 \%)$ apresentaram boa evolução em avaliação após 6 meses, 8 apresentaram evolução desfavorável (38\%) e 3 faleceram (14,2\%). Durante o seguimento, não se evidenciou diferença estatística na evolução entre pacientes operados antes e após 24 horas do ictus, nem entre lesões envolvendo o hemisfério dominante versus não dominante. Pacientes com mais de 60 anos e aqueles com Escala de Coma de Glasgow $(E C G)<8$ na avaliação pré-operatória apresentaram pior evolução após 6 meses $(p<0,05)$. A craniectomia descompressiva para infartos hemisféricos extensos aumentam a probabilidade de sobrevivência. Idade abaixo de 60 anos e ECG $\geq 8$ no exame pré-operatório e craniectomia descompressiva antes de sinais de herniação cerebral representam os principais fatores relacionados a uma melhor evolução clínica. Infarto hemisférico envolvendo o hemisfério dominante não representa um critério de exclusão. Palavras-chave: infarto cerebral, hemicraniectomia descompressiva, descompressão cirúrgica.

Ischemic stroke is a medical emergency and the most common affection of the central nervous system (CNS). This is the second-leading cause of death worldwide and the first cause of morbidity ${ }^{1}$. Ischemic stroke correspond to $85 \%$ of all strokes with a mortality of $10-50 \%$. Large space- occupying infarction accounts for 1-10\% of all supratentorial infarction with signs of elevated intracranial pressure (ICP) and brain herniation usually in the second to the fifth day leading to a mortality rate of $53 \%$ to $89 \%^{2-5}$. The high mortality rate makes some authors call this stroke as

\section{Correspondence}

Lucas Alverne Freitas de Albuquerque

Rua Silva Paulet 2140 / 1402

60120-021 Fortaleza CE - Brasil

E-mail: lucasalverne@yahoo.com.br

Received 13 May 2009

Received in final form 12 August 2009

Accepted 14 September 2009
Neurosurgery Division of Neurology and Neurosurgery Department, Campinas State University (UNICAMP), Campinas SP, Brazil: 'Assistant Neurosurgeon, Neurosurgery Department, UNICAMP; ${ }^{2}$ Resident of Neurosurgery, Neurosurgery Department, UNICAMP; ${ }^{3} \mathrm{MD}$, Federal University of Ceará (UFC), For taleza CE, Brazil; ${ }^{4}$ Medical Student, UFC; ${ }^{5}$ Professor of Neurosurgery, Neurosurgery Department, UNICAMP. 
"malignant" infarct and create the term malignant middle cerebral artery syndrome to describe the rapid development of fatal brain swelling ${ }^{6}$. Large space-occupying infarction is generally secondary to an occlusion of the carotid artery or the M1 segment of the middle cerebral artery (MCA), including or not the anterior cerebral artery (ACA) or the posterior cerebral artery (PCA). Neuroimaging criteria varies between the authors: infarct volume on diffusion-weighted magnetic resonance imaging (MRI) of more than $145 \mathrm{~cm}^{3}$; brain computed tomography (CT) ischemic changes affecting more than two-thirds of the MCA territory and including the basal ganglia; brain CT ischemic changes affecting at least two-thirds of the MCA territory with space-occupying edema; signs on CT of an infarct of at least $50 \%$ of the MCA territory, with or without additional infarction in the territory of the anterior or posterior cerebral artery on the same side $e^{5,7}$.

Many studies have suggested that decompressive surgery, consisting of a hemicraniectomy and duraplasty, reduces mortality and improves outcome in patients with massive brain infarctions ${ }^{5,8}$.

We report our series of 21 patients treated with decompressive craniectomy.

\section{METHOD}

\section{Study design}

In this retrospectively designed study, we describe the results of decompressive hemicraniectomy in $21 \mathrm{pa}-$ tients with large hemispheric infarctions at UNICAMP Medical School Hospital from March 2003 to September 2007. We have considered massive cerebral infarction as brain CT ischemic changes affecting at least two-thirds of the MCA territory with space-occupying edema or both MCA and ACA or PCA infarctions leading to a minimum of $50 \%$ hemispherical volume compromised. We analyzed gender, age, Glasgow Coma Scale (GCS) on admission and pre-surgical evaluation, clinical status on pre-surgical exam, time from initial symptoms to decompressive craniectomy, length of stay in the hospital and Glasgow Outcome Scale (GOS) 6 months after discharge. Data was subsequently analyzed for comparative study of patients with good to moderate outcome $(\mathrm{GOS} \geq 4)$ and patients with poor outcome $(\mathrm{GOS} \leq 3)$.

\section{Patient selection}

The decision to perform decompressive craniectomy was based on the presence of a space-occupying large

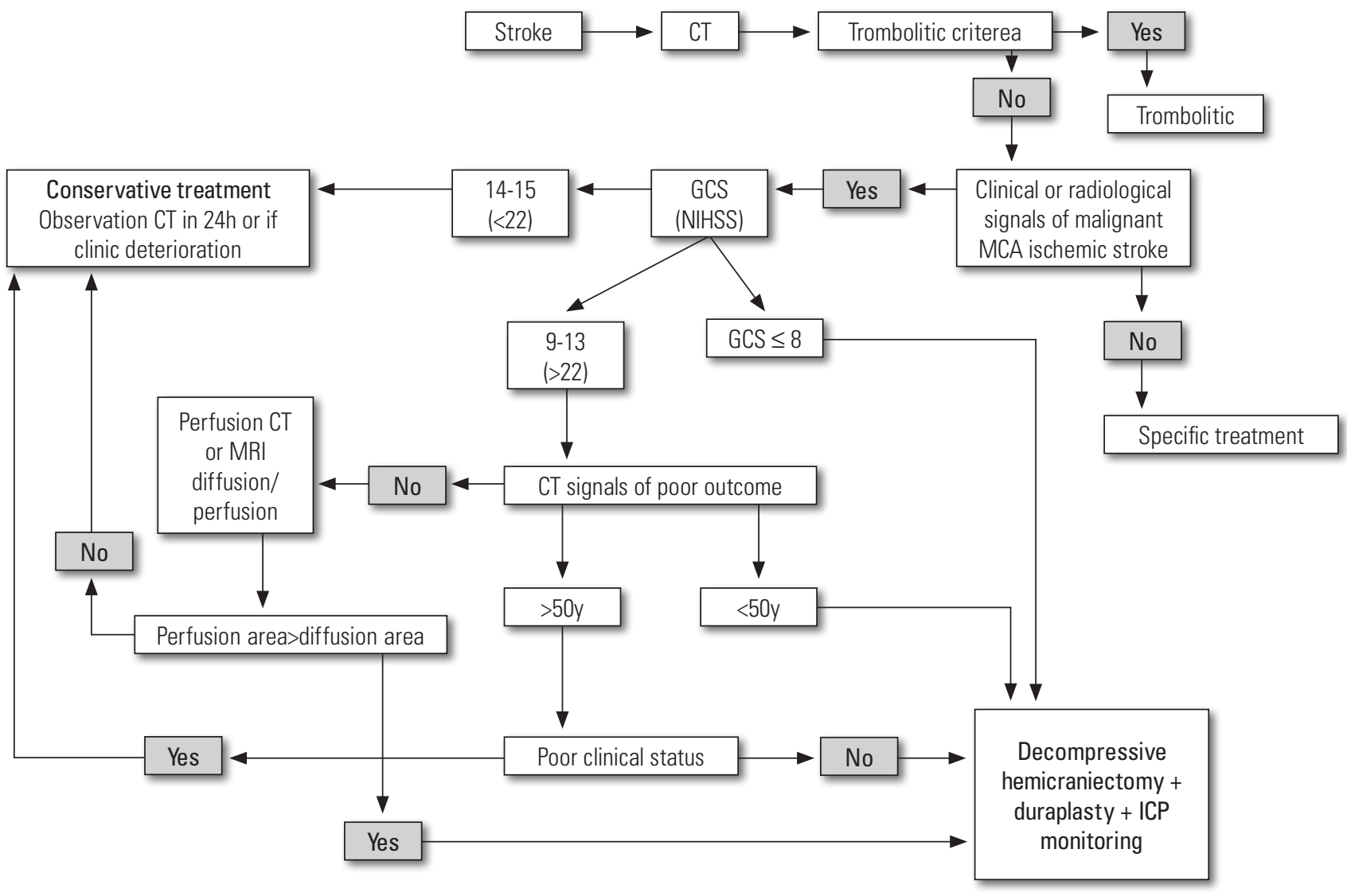

Fig 1. Approach to ischemic stroke. 
Table 1. Analyze of outcome.

\begin{tabular}{clc}
\hline Grade & Characteristics (6) & Outcome \\
\hline G1 & Functionally independent - BI $\geq 90$; or mRS 0-1; or GOS 5 & Good \\
G2 & Mild to moderate disability - BI=60 to 89; or mRS 2-3; or GOS 4 & Good \\
G3 & Severely disabled - BI <60; or mRS 4-5; or GOS 2 to 3 & Poor \\
G4 & Death & Poor \\
\hline
\end{tabular}

G1-4: grade 1-4; BI: Barthel index; mRS: modified Rankin score; GOS: Glasgow Outcome Scale.

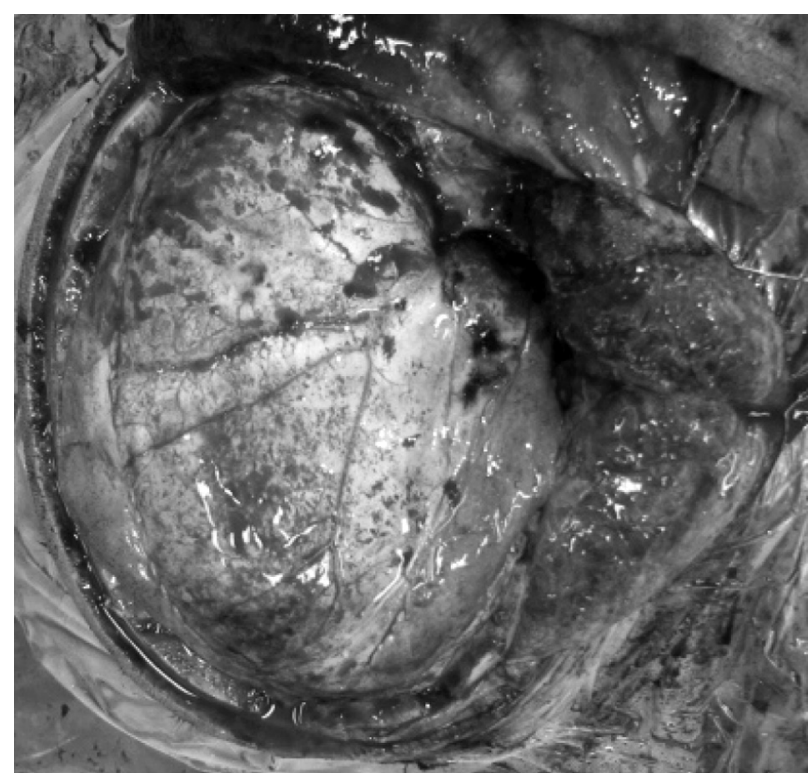

Fig 2. A right sided question mark incision. The skin flap and the temporal muscle were dissected on a separate manner to provide an increase in the exposure of the middle fossa. Than a duraplasty using aponeurotic galeal flap after decompressive craniectomy for brain expansion.

hemispheric infarction on CT scan and the clinical status of the patients. Patients with GCS $>13$ and no midline shift or basal cistern compression at initial evaluation were managed in the intensive care unit. Neurological deterioration or development of brain herniation signs were indications to decompressive craniectomy as patients initially presented with GCS $\leq 8$ and cistern compression or midline shift at CT scan. Figure 1 shows our approach to ischemic stroke. The patients presented with GCS between 9 and 13 were individually managed.

\section{Surgical technique}

A question mark-shaped skin flap based on the ear and a wide craniotomy was performed on the affected side with partial removal of the frontal, temporal, and parietal bones, so that the floor of the middle fossa could be exposed and the bone flap have a minimum of $12 \mathrm{~cm}$ diameter. The dura was opened in a "C" shape all over and $1 \mathrm{~cm}$ distant to the border of the craniotomy. Homologous temporal fascia was placed into the incision for volumeenlarged dural repair (Fig 2). The bone flap was placed in a subcutaneous pocket overlying the abdomen for preservation until subsequent cranioplasty.

\section{Data analysis}

To make possible the comparison between the different studies, the outcomes were classified into 4 specific categories (Table 1): grade 1 (G1) functionally independent; grade 2 (G2) mild to moderate disability; grade 3 (G3) severely disabled; and grade 4 (G4) death ${ }^{8}$. Good outcomes were defined as functionally independent or mild to moderate disability. Poor outcomes were defined as severe disability or death. It was not necessary that the study fulfill all the criteria listed, for instance, a G1 outcome could be based only on a GOS of 5 , or only on a Barthel index $>90$, or on a mRS 0-1, not been necessary all three classifications.

\section{Statistical analysis}

All data are expressed as mean \pm standard deviation (SD). Mann-Whitney U non-parametric tests, t tests and Fisher's exact test were used for analysis of statistical evidence, with $\mathrm{p}<0.05$ considered significant. Statistical software, SPSS 14.0 (SPSS Inc., Chicago, IL) was used for statistical analysis.

\section{RESULTS}

A total of 21 patients (16 males and 5 females) were submitted to decompressive craniectomy during the period analyzed by the study (Table 2). The mean age was $50.09 \pm 14.29$ years. On admission, the mean GCS was $12 \pm$ 2.42 points (range from 6 to 14 ).

The mean GCS on immediate pre-surgical evaluation was $8 \pm 2.19$ points. Nine patients $(42.85 \%)$ presented with pupillary changes on pre-surgical evaluation; afasia occurred in six cases $(28.5 \%)$ and hemiplegia presented in all patients.

Seventeen patients (80.95\%) had "malignant" MCA infarction and 4 (19.04\%) had associated ACA territory infarction. The dominant hemisphere was affected in 6 cases (28.5\%) and the non-dominant hemisphere in 15 cases (71.4\%). 
Table 2. Characteristics of 21 patients included in the study.

\begin{tabular}{|c|c|c|c|c|c|c|c|c|c|c|}
\hline Pct & Gender & Age & $\begin{array}{l}\text { Stroke } \\
\text { side }\end{array}$ & $\begin{array}{l}\text { Admission } \\
\text { GCS }\end{array}$ & $\begin{array}{l}\text { GCS before } \\
\text { surgery }\end{array}$ & Pupils & $\begin{array}{l}\text { Time to } \\
\text { surgery }\end{array}$ & $\begin{array}{c}\text { GCS after } \\
\text { surgery }\end{array}$ & $\begin{array}{c}\text { discharge } \\
\text { (days) }\end{array}$ & GOS \\
\hline 1 & Male & 56 & Right & 14 & 8 & Isocoria & $<24 h$ & 15 & 14 & 4 \\
\hline 2 & Male & 28 & Left & 13 & 8 & Isocoria & $<24 h$ & 15 & 33 & 3 \\
\hline 3 & Female & 48 & Right & 13 & 7 & Isocoria & $<24 h$ & 15 & 42 & 4 \\
\hline 4 & Female & 59 & Left & 9 & 6 & Anisocoria & $48-72 h$ & 11 & 24 & 3 \\
\hline 5 & Male & 53 & Right & 14 & 8 & Anisocoria & $48-72 h$ & 15 & 34 & 4 \\
\hline 6 & Male & 56 & Right & 11 & 11 & Isocoria & 24-48h & 15 & 7 & 4 \\
\hline 7 & Male & 35 & Right & 15 & 8 & Isocoria & $<24 h$ & 15 & 28 & 4 \\
\hline 8 & Male & 42 & Left & 14 & 8 & Anisocoria & $24-48 h$ & 12 & 23 & 3 \\
\hline 9 & Male & 21 & Right & 15 & 6 & Anisocoria & $48-72 h$ & 15 & 16 & 4 \\
\hline 10 & Male & 30 & Right & 12 & 11 & Anisocoria & $24-48 h$ & 15 & 15 & 4 \\
\hline 11 & Female & 39 & Right & 9 & 6 & Anisocoria & $72-96 h$ & Die & 13 & 1 \\
\hline 12 & Male & 71 & Left & 10 & 7 & Anisocoria & $72-96 h$ & Die & 8 & 1 \\
\hline 13 & Male & 56 & Right & 14 & 12 & Isocoria & $<24 h$ & 15 & 10 & 3 \\
\hline 14 & Female & 47 & Right & 13 & 8 & Isocoria & $<24 h$ & 8 & 109 & 2 \\
\hline 15 & Male & 63 & Right & 10 & 6 & Anisocoria & $<24 h$ & 6 & 65 & 2 \\
\hline 16 & Male & 79 & Right & 15 & 5 & Anisocoria & $<24 h$ & Die & 10 & 1 \\
\hline 17 & Male & 44 & Left & 10 & 10 & Isocoria & $<24 h$ & 11 & 15 & 4 \\
\hline 18 & Male & 58 & Right & 13 & 13 & Isocoria & $<24 h$ & 15 & 13 & 4 \\
\hline 19 & Male & 61 & Right & 6 & 6 & Isocoria & 24-48h & 12 & 21 & 3 \\
\hline 20 & Female & 48 & Left & 10 & 7 & Isocoria & $48-72 h$ & 11 & 16 & 3 \\
\hline 21 & Male & 58 & Right & 12 & 7 & Isocoria & $24-48 h$ & 14 & 25 & 4 \\
\hline
\end{tabular}

Pct: patient; GCS: Glasgow Coma Scale; GOS: Glasgow Outcome Scale.

Time between onset of symptoms and decompressive craniectomy was less than 24 hours in 10 (47.61\%), 24-48 hours in 5 (23.8\%), 48-72 hours in 4 (19\%) and 72-96 hours in 2 cases $(9.52 \%)$. We have considered that early surgery was a decompressive craniectomy in the absence of brain herniation signs and in patients with GCS $>8$ despite the length of hospital stay. It was carried out in 12 cases and late surgery in other 9 patients. Length of stay in the hospital was of $25.76 \pm 23.3$ days. Surgery improved significantly the GCS of patients comparing the immediate preoperative scores $(8.0 \pm 2.19)$ and immediate post-operative GCS (11.62 \pm 4.41$),(\mathrm{p}<0.05)$. Occurrence of GCS $<9$ in the pre-surgical evaluation was associated to a higher length of hospital stay $(30.06 \pm 25.3$ versus $12.0 \pm 3.46, \mathrm{p}<0.05)$.

There was no statistical significance in the outcome between men and women, surgery before and after 24 hours of ictus, left and right side stroke groups ( $p>0.05$ ). Patients older than 60 years presented worst outcome at six months $(1.75 \pm 0.957$ versus $3.41 \pm 0.87$ points in GOS, $\mathrm{p}<0.05)$. The presence of brain herniation signs represented a variable associated to poor prognosis, but statistical significance was not reached in this study $(2.59 \pm 1.33$ versus $3.5 \pm 0.67$ points in GOS, in patients with and without pupillary changes, respectively; $\mathrm{p}=0.09$ ). According to the Mann-Whitney test, the group of patients who had a poor GCS in the pre-surgical evaluation presented a trend toward poor prognosis, however statistical significance was not demonstrated $(2.88 \pm 1.14$ versus $3.8 \pm 0.44$ points in GOS, $p=0.08$ ). However, when GCS $\leq 7$ is used to predict poor prognosis, we reached statistical evidence $(2.72 \pm 1.27 \times 3.54 \pm 0.68$ points in GOS, $\mathrm{p}<0.05)$.

Ten patients $(47.61 \%)$ presented a good outcome at the 6 months evaluation. Eight patients who survived had a poor outcome (38\%). Three patients of our series died (14.2\%) after the surgical procedure, secondary to the presented brain lesion and hemodynamic failure.

\section{DISCUSSION}

Patients with massive space-occupying hemispheric infarction have a poor prognosis, as mass effect usually develops rapidly with occurrence of clinical deterioration in the first 2 to 4 days $^{5,9,10}$. Decompressive surgery has been studied as a way to relieve the intracranial hypertension and tissue shifts related to mass lesions. Bendszus et al. in a case report study, analyzing perfusion CT before and after decompressive craniectomy showed the value of this procedure to spare the ischemic but not infarcted area ${ }^{11}$.

Non-randomized studies suggest that late and early decompressive surgery reduces mortality and increases the number of patients with a favorable functional outcome after massive hemispheric infarction compared to the conservative treatment ${ }^{4,5,8,10,12}$. Indeed, early decompressive surgery with duraplasty is related with even a better outcome ${ }^{9,12}$.

Several conservative measures have been proposed to limit brain tissue shifts and reduce intracranial pressure, 
Table 3. Conservative treatment of massive cerebral infarction.

\begin{tabular}{|c|c|c|c|c|c|}
\hline Paper & Study design & Patients & Mean age & Mortality & Survivors outcome \\
\hline Rieke et al. ${ }^{4}$ & Open, nonrandomized, control trial & $21 / 53$ & 49 & $76 \%$ & G1:0\%; G2:10\%; G3:14\% \\
\hline Holtkamp et al. ${ }^{2}$ & Retrospective descriptive study & $12 / 24$ & 65 & $83 \%$ & G1:0\%; G2:0\%; G3:17\% \\
\hline Kuroki et al. ${ }^{3}$ & Retrospective/prospective descriptive study & $7 / 15$ & 79 & $85 \%$ & G1:0\%; G2:0\%; G3:15\% \\
\hline $\mathrm{HAMLET}^{7}$ & Multicenter prospective randomized open study & $9 / 23$ & 43 & $89 \%$ & G1:0\%; G2:11\%; G3:0\% \\
\hline DECIMAL $^{16}$ & Multicenter prospective randomized open study & $18 / 38$ & 43 & $78 \%$ & G1:0\%; G2:22\%; G3:0\% \\
\hline DESTINY15 & Multicenter prospective randomized open study & $15 / 32$ & 46 & $53 \%$ & G1:0\%; G2:27\%; G3:20\% \\
\hline Vahedi et al. ${ }^{5}$ & Metanalysis of randomized trial & $42 / 93$ & 44 & $71 \%$ & G1:0\%; G2: 21\%; G3:7\% \\
\hline Total & - & 82 & 51 & $75 \%$ & G1:0\%; G2:13\%; G3:11\% \\
\hline
\end{tabular}

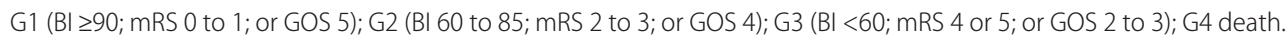

Table 4. Surgical treatment of malignant middle cerebral artery infarction.

\begin{tabular}{|c|c|c|c|c|c|c|}
\hline Paper & Study design & Pcts & $\begin{array}{l}\text { Mean } \\
\text { age }\end{array}$ & $\begin{array}{l}\text { Treatment } \\
\text { indication }\end{array}$ & Mort & Survivors outcome \\
\hline Rieke et al. ${ }^{4}$ & Open, nonrandomized, control trial & $32 / 53$ & 49 & Late surgery & $34 \%$ & G1:0\%; G2:18\%; G3 47\% \\
\hline Holtkamp et al. ${ }^{2}$ & Retrospective descriptive study & $12 / 24$ & 65 & Late surgery & $33 \%$ & G1:0\%; G2 + G3: 67\% \\
\hline Kuroki et al. ${ }^{3}$ & $\begin{array}{l}\text { Retrospective/prospective } \\
\text { descriptive study }\end{array}$ & $8 / 15$ & 72 & Late surgery & $12 \%$ & G1:0\%; G2:44\%; G3:44\% \\
\hline Uhl et al. ${ }^{24}$ & $\begin{array}{l}\text { Multicenter retrospective } \\
\text { descriptive study }\end{array}$ & 188 & 57 & Late surgery & $37 \%$ & G1:1,6\%; G2:18\%; G3:49\% \\
\hline Woertgen et al. ${ }^{17}$ & Retrospective descriptive study & 48 & 48 & Late surgery & $26 \%$ & G1:7\%; G2:18\%; G3:50\% \\
\hline Kilincer et al. ${ }^{9}$ & Non-randomized prospective study & 32 & 58 & Late surgery & $50 \%$ & G1:0\%; G2:0\%; G3: 50\% \\
\hline Gupta et al. ${ }^{8}$ & $\begin{array}{l}\text { Metanalysis of non randomized } \\
\text { trials and retrospective study }\end{array}$ & 138 & 50 & $\begin{array}{l}\text { Review of } \\
12 \text { studies }\end{array}$ & $24 \%$ & G1:7\%; G2:35\%; G3:34\% \\
\hline $\mathrm{HAMLET}^{7}$ & $\begin{array}{l}\text { Multicenter prospective } \\
\text { randomized open study }\end{array}$ & $14 / 23$ & 51 & Randomized & $21 \%$ & G1:0\%; G2:29\%; G3:50\% \\
\hline DECIMAL ${ }^{16}$ & $\begin{array}{l}\text { Multicenter prospective } \\
\text { randomized open study }\end{array}$ & $20 / 38$ & 43 & Randomized & $25 \%$ & G1:0\%; G2:50\%; G3:25\% \\
\hline DESTINY15 & $\begin{array}{l}\text { Multicenter prospective } \\
\text { randomized open study }\end{array}$ & $17 / 32$ & 43 & Randomized & $18 \%$ & G1:0\%; G2:48\%; G3:35\% \\
\hline Vahedi et al. ${ }^{5}$ & Metanalysis of 3 randomized trial & $51 / 93$ & 45 & $\begin{array}{l}\text { Review of } 3 \\
\text { randomized } \\
\text { studies }\end{array}$ & $22 \%$ & G1:0\%; G2:43\%; G3:35\% \\
\hline Our institution & Retrospective descriptive study & 21 & 50 & Late surgery & $14 \%$ & G1:0\%; G2:47\% ;G3:38\% \\
\hline Total & Non-randomized & 435 & 54 & & $31 \%$ & G1:3\%; G2:24\% ;G3:44\% \\
\hline Total & Randomized & 51 & 45 & & $22 \%$ & G1:0\%; G2:43\%; G3:35\% \\
\hline Total & - & 486 & 53 & & $30 \%$ & G1:3\%; G2:25\% ;G3:43\% \\
\hline
\end{tabular}

Pcts: patients; Mort: mortality. G1 (BI 290; mRS 0 to 1; or GOS 5); G2 (BI 60 to 85; mRS 2 to 3; or GOS 4); G3 (BI <60; mRS 4 or 5; or GOS 2 to 3); G4 death. Late surgery: signals of brain herniation; early surgery: before the firsts signals of brain herniation. The study of Rieke et al and Holtkamp et al. are already included in the study of Gupta et al. The HAMLET, DECIMAL and DESTINY are included in the metanalysis of Vahedi et al.

including intensive care therapy, mild bed elevation, sedation, hyperventilation, osmotic therapy, hypothermia and others. However, conservative treatment for massive brain infarction has been reported (Table 3) with a high mortality rate and poor outcome despite all those measures, suggesting that they are of limited value ${ }^{6,13,14}$.

The three randomized trials, DECIMAL, DESTINY and HAMLET confirm these findings. DECIMAL and DESTINY were interrupted because of a significant difference in mortality favoring decompressive surgery and HAMLET is still ongoing and aims to include 112 patients $^{5,7,15,16}$.

Several trials (Table 4) have described the effects of decompressive surgery on functional outcome after space-occupying infarction. As shown in Tables 3 and 4, the decompressive surgery increases the probability of survival from $25 \%$ to nearly $70 \%$ and the probability of a good outcome (G1 and G2) from 13\% to $28 \%$; however, the probability of surviving in a condition requiring as- 
sistance and severe disability (G3) increases from 11\% to $43 \%$, probably due to the higher number of survivors. Therefore, information about quality of life of survivors is essential for guiding the therapeutic decision ${ }^{5}$. In spite of previous reports in the literature differ with respect to the functional outcome and quality of life after decompressive surgery for space-occupying infarction ${ }^{5,17}$, even patients with aphasia may improve significantly ${ }^{18}$.

It is unclear which groups of patients benefit most from the procedure. Vahedi et al. ${ }^{5}$ demonstrated that surgery was beneficial $(\mathrm{p}<0.01)$ independently of age (above and below 50 years), presence of aphasia, and time to randomization (above and below $24 \mathrm{~h}$ ) when compared to conservative treatment. Kuroki et al. ${ }^{3}$ describe that the decompressive surgery outcome is better than the conservative treatment even in patient with more than 70 years old. Patients with the larger infarctions as found in the internal carotid artery (ICA) infarct were more likely to have a poorer prognosis as expected and according to Kilincer et al. ${ }^{9}$ surgery for an ICA infarction is not beneficial, unless exceptional cases as very young age, nondominant hemisphere, and good clinical condition.

Identification of patients at high risk of malignant edema based on radiographic and clinical criteria might allow early hemicraniectomy, defined as a surgery performed before signs of brain stem herniation, as a mean of improving mortality and patient outcome $e^{6,9,10,12,19}$. According to Schwab et al. ${ }^{10}$, early hemicraniectomy also reduces the time of critical care therapy from 13.3 to 7.4 days. Although no statistical significance was reached, we observed an important trend toward poor prognosis in the group of patients that had pupillary changes $(\mathrm{p}=0.09)$.

Radiographic signs such as early hypodensity of $>50 \%$ of the MCA territory and/or additional vascular territories $(\mathrm{ACA} \text { or PCA })^{12,19-24}$, ICA infarct 9, midline shift $\geq 10$ $\mathrm{mm}^{9,19}$, effacement of subarachnoid space 19,20, attenuation of corticomedullary differentiation ${ }^{19,20}$, presence of hydrocephalus ${ }^{19,25}$ may predict which patients will develop malignant edema or bad outcome. Infarct volume of more than $200 \mathrm{~cm}^{3}$ has $91 \%$ accuracy to predict malignant hemispheric infarction ${ }^{12}$ and the extent of infarct of more than two-thirds of MCA territory has a sensitivity of $93 \%$ and specificity of $95 \%$ and they are the two most sensitive and specific single explanatory variable for prediction of mortality ${ }^{19}$. On the other hand, brain edema is maximized after 24-72 hours ${ }^{19}$, so an early CT examination should not be considered sensitive enough to predict the final outcome $\mathrm{e}^{19,20,25}$.

Clinical signs such as early clinical deterioration ${ }^{9}$, early nausea or vomiting ${ }^{22,23}$, and a National Institute of Health Stroke Scale (NIHSS) score $\geq 20$ for left ${ }^{22,25}$ or $\geq 15$ for right hemisphere infarction ${ }^{22}$, pre-operative GCS score $\leq 7^{9}$, hypertension or heart failure, and increased pe- ripheral white blood cell count ${ }^{12,22}$, also may predict which patients will develop malignant edema or have a poor outcome. Lam et al. ${ }^{19}$ indicate that a NIHSS $>22$ is predictive of high mortality. In our study, patients who presented GCS $<8$ in the pre-surgical exam demonstrated a tendency toward poor outcome, which in our view indicates that the surgical approach should not be delayed until neurological deteriorations occurs.

Although elevated ICP was correlated with higher mortality ${ }^{26}$, ICP monitoring should not be the only parameter in the determination of surgical timing as clinical signs of deterioration or herniation can precede the increase in $\mathrm{ICP}^{27}$.

Time from stroke to surgery has also been studied before. Non-randomized series have suggested that outcome is substantially improved if surgical treatment is initiated within $24 \mathrm{~h}$ of stroke onset as compared with longer time windows for treatment ${ }^{5,10,17}$. Schwab et al. ${ }^{10}$ presented benefits of decompression before 24 hours after stroke. In a group of 31 patients, $26(84 \%)$ had a BI $>60$ at follow up in their study. Gupta et al. ${ }^{8}$, however, did not show benefit to surgery<24 hours, probably due to a greater proportion of patients (64\%) with signs of herniation before surgery in his group. Vahedi et al. ${ }^{5}$ in a systematic review, conclude that the timing of surgery did not affect outcome. We did not observe difference in outcome between patients submitted to surgery before or after 24 hours. We believe the reason for the no significant difference in timing of surgery was the poor general clinical status of patients who presented early to our department. In our view, timing between clinical deterioration and surgery and immediate pre-operative GCS are both more relevant factors than timing from stroke to surgery.

The age has been demonstrated to be an important predictor of outcome in decompressive hemicraniectomy. There are reports of poor functional outcomes and increased mortality in older patients compared to younger ${ }^{2,28}$. The cut-off point age to predict a good outcome is uncertain. Wijdicks and Diringer ${ }^{29}$ studied the natural history of 42 patients with MCA territory infarction, 3 of 11 patients $(28 \%)<45$ years died, whereas 20 of 22 patients $>45$ years, $90.9 \%$ died. Important studies suggest that the optimal recovery occurs in patients less than 50 years ${ }^{8,24,28,30}$. However, Holtkamp et al. ${ }^{2}$ use a cutoff point of 55 years and Kilincer et al. ${ }^{9}$, when selected 60 years as a cut-off point, provided one of the strongest predictors of outcome. In our series, there was no statistical difference when used a cut-off age of 50 years. However, patients older than 60 years presented worst outcome at six months follow up.

Offering life-saving treatment for large dominant hemisphere infarcts is controversial, mainly because surgery may leave patients with an unacceptable poor quali- 
ty of life because of hemiplegia and aphasia ${ }^{28}$. The side of the infarct did not have prognostic relevance in our study, as demonstrated by other series ${ }^{8,9,17,24}$. In Gupta et al. ${ }^{8}$ review, the 27 patients who had decompression of the dominant hemisphere had functional outcome similar to the 111 patients who had non-dominant infarcts. In Kilincer et al. ${ }^{9}$, half of the patients had dominant hemispheric infarction with global aphasia preoperatively, 6/7 patients in the good outcome group had a dominant hemispheric infarction and most of the patients showed considerable improvements in their aphasia, a finding confirmed by other authors ${ }^{4,10,18,31}$. Therefore, we believe infarction side should not be exclusion criteria for surgery. We agree with some authors that language deficits may be of small consequence in patients who are severely disabled by hemiplegia; also, non-dominant hemisphere strokes can lead to severe depressive, abulic, or neglect states that may interfere with rehabilitation efforts and are as disabling as aphasia ${ }^{8,32}$. On the other side, global disability scales such as the BI, mRS, and GOS may emphasize mobility as opposed to language dysfunction ${ }^{8,9}$.

It is not clear which patients may avoid severe disability after the procedure. A large number of patients or relatives (70\%) stated that they would undergo the procedure again if faced to the same situation ${ }^{8}$. Even $79 \%$ of the patients and their family are satisfied with the surgical results ${ }^{33}$.

In conclusion, decompressive craniectomy for spaceoccupying large hemispheric infarction increases the probability of survival that can yield good functional outcomes in some cases. Careful patient selection, made on an individual basis, and early operation may improve the functional outcome for large hemispheric infarction. Information about quality of life of survivors is essential for guiding such decisions because most patients require extensive rehabilitative therapy and lifelong assistance.

There are limitations in our study. Although we present important data about decompressive surgery, it is a non-randomized retrospective study with results that need confirmation by larger randomized trials. Although there is not a consensus for the surgical treatment of massive hemispheric infarction, we recommend: (1) in patients under 60 years old; (2) in patients with CT scan evidence of massive cerebral infarction with GCS $\geq 8$; (3) decompressive craniectomy before signs of brain herniation if possible. Dominant hemispheric infarction does not represent an exclusion criteria.

\section{REFERENCES}

1. Murray CJ, Lopez AD. Mortality by cause for eight regions of the world: Global Burden of Disease Study. Lancet 1997:349:1269-1276.

2. Holtkamp M, Buchheim K, Unterberg A, et al. Hemicraniectomy in elderly patients with space occupying media infarction: improved survival but poor functional outcome J Neurol Neurosurg Psychiatry 2001;70:226-228.

3. Kuroki $\mathrm{K}$, Taguchi H, Sumida M, et al. [Decompressive craniectomy for massive infarction of middle cerebral artery territory]. No Shinkei Geka 2001;29:831-835.
4. Rieke K, Schwab S, Krieger D, et al. Decompressive surgery in space-occupying hemispheric infarction: results of an open, prospective study. Crit Care Med 1995:23:1576-1587.

5. Vahedi K, Hofmeijer J, Juettler E, et al. Early decompressive surgery in malignant infarction of the middle cerebral artery: a pooled analysis of three randomised controlled trials. Lancet Neurol 2007:6:215-222.

6. Hacke W, Schwab S, Horn M, Spranger M, De Georgia M, von Kummer R. 'Malignant' middle cerebral artery infarction: clinical course and prognostic signs. Arch Neurol 1996;53:309-315.

7. Hofmeijer J, Amelink GJ, Algra A, et al. HAMLET investigators. Hemicraniectomy after middle cerebral artery infarction with Life-threatening Edema Trial (HAMLET): protocol for a randomised controlled trial of decompressive surgery in space-occupying hemispheric infarction. Trials Sep 2006;11:7-29.

8. Gupta R, Connolly ES, Mayer S, Elkind MS. Hemicraniectomy for massive middle cerebral artery territory infarction: a systematic review. Stroke 2004; 35:539-543.

9. Kilincer C, Asil T, Utku U, et al. Factors affecting the outcome of decompressive craniectomy for large hemispheric infarctions: a prospective cohort study. Acta Neurochir (Wien) 2005;147:587-594.

10. Schwab S, Steiner T, Aschoff A, et al. Early hemicraniectomy in patients with complete middle cerebral artery infarction. Stroke 1998;29:1888-1893.

11. Bendszus M, Mullges W, Goldbrunner R, Weigand A, Solymosi L. Hemodynamic effects of decompressive craniotomy in MCA infarction: evaluation with perfusion CT. Eur Radiol 2003;13:1895-1898.

12. Mori K, Nakao Y, Yamamoto T, Maeda M. Early external decompressive craniectomy with duroplasty improves functional recovery in patients with massive hemispheric embolic infarction: timing and indication of decompressive surgery for malignant cerebral infarction. Surg Neurol 2004;62:420-430.

13. Berrouschot J, Sterker M, Bettin S, Köster J, Schneider D. Mortality of spaceoccupying ('malignant') middle cerebral artery infarction under conservative intensive care. Intensive Care Med 1998:24:620-623.

14. Hofmeijer J, van der Worp HB, Kappelle LJ. Treatment of spaceoccupying cerebral infarction. Crit Care Med 2003;31:617-625.

15. Jüttler E, Schwab S, Schmiedek P, et al. Decompressive Surgery for the Treatment of Malignant Infarction of the Middle Cerebral Artery (DESTINY): a randomized, controlled trial. Stroke 2007:38:2518-2525.

16. Vahedi $K$, Vicaut E, Mateo J, et al. Sequential-design, multicenter, randomized, controlled trial of Early Decompressive Craniectomy in Malignant Middle Cerebral Artery Infarction (DECIMAL Trial). Stroke 2007:38:2506-2517.

17. Woertgen C, Erban P, Rothoerl RD, Bein T, Horn M, Brawanski A. Quality of life after decompressive craniectomy in patients suffering from supratentorial brain ischemia. Acta Neurochir (Wien) 2004;146:691-695

18. Kastrau F, Wolter M, Huber W, Block F. Recovery from aphasia after hemicraniectomy for infarction of the speech-dominant hemisphere. Stroke 2005; 36:825-829.

19. Lam WW, Leung TW, Chu WC, Yeung DT, Wong LK, Poon WS. Early computed tomography features in extensive middle cerebral artery territory infarct: prediction of survival. J Neurol Neurosurg Psychiatry 2005;76:354-357.

20. Haring HP, Dilitz E, Pallua A, et al. Attenuated corticomedullary contrast: An early cerebral computed tomography sign indicating malignant middle cerebral artery infarction. A case-control study. Stroke 1999:30:1076-1082.

21. Kasner SE, Demchuk AM, Berrouschot J, et al. Predictors of fatal brain edema in massive hemispheric ischemic stroke. Stroke 2001;32:2117-2123.

22. Krieger DW, Demchuk AM, Kasner SE, Jauss M, Hantson L. Early clinical and radiological predictors of fatal brain swelling in ischemic stroke. Stroke 1999; 30:287-292.

23. Robertson SC, Lennarson P, Hasan DM, Traynelis VC. Clinical course and surgical management of massive cerebral infarction. Neurosurgery 2004;55:55-62.

24. Uhl E, Kreth FW, Elias B, et al Outcome and prognostic factors of hemicraniectomy for space occupying cerebral infarction. J Neurol Neurosurg Psychiatry 2004; $75: 270-274$

25. Barber PA, Demchuk AM, Zhang J, et al. Computed tomographic parameters predicting fatal outcome in middle cerebral artery infarction. Cerebrovasc Dis 2003;16:230-235.

26. Frank JI. Large hemispheric infarction, deterioration, and intracranial pressure. Neurology 1995:45:1286-1290.

27. Schwab S, Aschoff A, Spranger M, Albert F, Hacke W. The value of intracranial pressure monitoring in acute hemispheric stroke. Neurology 1996:47:393-398.

28. Carter BS, Ogilvy CS, Candia GJ, Rosas HD, Buonanno F. One-year outcome after decompressive surgery for massive non-dominant hemispheric infarction. Neurosurgery 1997:40:1168-1176.

29. Wijdicks EF, Diringer MN. Middle cerebral artery territory infarction and early brain swelling: progression and effect of age on outcome. Mayo Clin Proc 1998;73:829-836.

30. Pranesh M B, Dinesh Nayak S, Mathew V, et al. Hemicraniectomy for large middle cerebral artery territory infarction: outcome in 19 patients. J Neurol Neurosurg Psychiatry 2003;74:800-802

31. Kalia KK, Yonas H. An aggressive approach to massive middle cerebral artery infarction. Arch Neurol 1993:50:1293-1297.

32. Walz B, Zimmermann C, Böttger S, Haberl RL. Prognosis of patients after hemicraniectomy in malignant middle cerebral artery infarction. J Neurol 2002:249:1183-1190

33. Matsuura $D$, Inatomi $Y$, Yonehara $T$, et al. [Decompressive craniectomy for ischemic stroke]. No To Shinkei 2006:58:305-310. 